\title{
Modeling and detection of regional depth phases at the GERES array
}

\author{
M.-T. Apoloner and G. Bokelmann \\ Department of Meteorology and Geophysics, University of Vienna, Vienna, Austria \\ Correspondence to: M.-T. Apoloner (maria-theresia.apoloner@univie.ac.at)
}

Received: 8 June 2015 - Revised: 27 July 2015 - Accepted: 31 July 2015 - Published: 31 August 2015

\begin{abstract}
The Vienna Basin in Eastern Austria is a region of low to moderate seismicity, and hence the seismological network coverage is relatively sparse. Nevertheless, the area is one of the most densely populated and most developed areas in Austria, so accurate earthquake location, including depth estimation and relation to faults is not only important for understanding tectonic processes, but also for estimating seismic hazard. Particularly depth estimation needs a dense seismic network around the anticipated epicenter. If the station coverage is not sufficient, the depth can only be estimated roughly. Regional Depth Phases (RDP) like sPg, sPmP and sPn have been already used successfully for calculating depth even if only observable from one station. However, especially in regions with sedimentary basins these phases prove difficult or impossible to recover from the seismic records.

For this study we use seismic array data from GERES. It is $220 \mathrm{~km}$ to the North West of the Vienna Basin, which - according to literature - is a suitable distance to recover $\mathrm{PmP}$ and $\mathrm{sPmP}$ phases. We use array processing on recent earthquake data from the Vienna Basin with local magnitudes from 2.1 to 4.2 to reduce the SNR and to search for RDP. At the same time, we do similar processing on synthetic data specially modeled for this application. We compare real and synthetic results to assess which phases can be identified and to what extent depth estimation can be improved. Additionally, we calculate a map of lateral propagation behavior of RDP for a typical strike-slip earthquake in our region of interest up to $400 \mathrm{~km}$ distance.

For our study case RDP propagation is strongly azimuthally dependent. Also, distance ranges differ from literature sources. Comparing with synthetic seismograms we identify $\mathrm{PmP}$ and $\mathrm{PbP}$ phases with array processing as strongest arrivals. Although the associated depth phases cannot be identified at this distance and azimuth, identification
\end{abstract}

of the $\mathrm{PbP}$ phases limits possible depth to less than $20 \mathrm{~km}$. Polarization analysis adds information on the first arriving Pn wave for local magnitudes above 2.5.

\section{Introduction}

Earthquake locations are fundamental for assessing seismic hazard. To provide these, areas with high seismicity rates and large magnitudes are instrumented with seismic stations. Particularly depth estimation requires a dense seismic network around the suspected epicenter. In contrast our study area, the Vienna Basin in Austria, a region of low to moderate seismicity with a largest instrumentally recorded magnitude around 5 , is only covered sparsely with seismic stations. Nevertheless, the area is one of the most densely populated and most developed areas in Austria. In areas like these, estimation of seismic hazard has to be based on location of earthquakes with small magnitudes.

Regional Depth Phases (RDP) like sPg, sPmP and sPn are $P$ phases converted to $S$ at the surface. They develop at different regional distance ranges (Ma and Atkinson, 2006) and the time difference between direct and reflected phase is sensitive to epicentral depth. This property already has been successfully used for calculating depth even if an RDP is observable at least at one station. However, especially in regions with sedimentary basins, these phases prove difficult or impossible to recover from the seismic records. On the other hand, seismic arrays together with appropriate processing can be used to lower signal to noise ratio of seismic recordings and so help detect and identify phases as e.g., Rost and Thomas (2002) describes. 


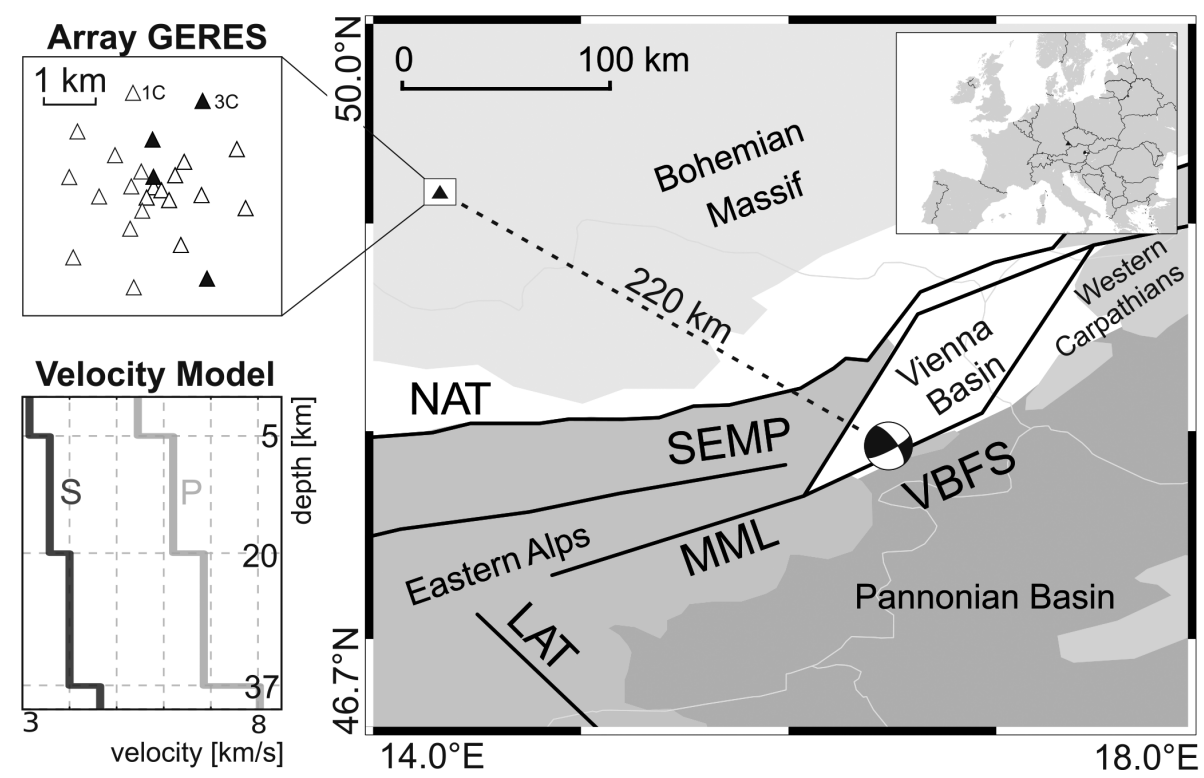

Figure 1. Right panel: schematic map of the Vienna Basin with surrounding tectonic units and main faults shown together with the focal mechanism of the Ml 4.2 earthquake from 20 Septmeber 2013 in Ebreichsdorf by Hausmann et al. (2014). Top left: layout of seismic array GERES with 1-component stations (white triangles) and 3-component stations (black triangles). Bottom left: $P$ and $S$ velocity model for the area by Hausmann et al. (2010)

The purpose of this study is to investigate the possibility of using a seismic array for identifying RDP in our region of interest.

In our study area we previously investigated a series of strike-slip earthquakes and relocated them (Apoloner and Bokelmann, 2015) using local stations. From this dataset we select all earthquakes with local magnitudes from 2.0 to 4.2 and analyse the records at the $220 \mathrm{~km}$ distant seismological array GERES (Harjes, 1990). According to the literature (Ma and Atkinson, 2006) those events should have a suitable magnitude and distance to recover PmP and sPmP phases. We use array processing on the whole array and polarization analysis on the four 3-component stations. At the same time, we perform similar processing of synthetic data specially modeled for this application. We compare real and synthetic results to assert which phases can be identified.

\section{Tectonic setting}

Ongoing convergence between the Bohemian Massif on the European Plate in the north and the Adriatic Plate in the south lead to lateral extrusion of crustal blocks to the east (e.g. Brückl et al., 2010), into the Pannonian Basin as is shown in Fig. 1. Two main sinistral strike-slip faults show this process: the Salzach-Enns-Mariazell-Puchberg (SEMP) fault and the seismically active Mur-Mürz-Lineament (MML). In the northwestern extension of those faults a pull-apart basin, the Vienna Basin started forming and now is filled with sedimentary layers of a few kilometers. Beneath this basin the MML branches into the Vienna Basin Fault System (VBFS) which produces moderate seismic events with local magnitudes around 4.0. The Bohemian Massif extends beneath the Northern Alpine Transition (NAT) and forms the crystalline basement beneath the Vienna Basin (Wessely, 1983).

To approximate the underground between Ebreichsdorf and GERES we used the model proposed by Hausmann et al. (2010), which is a 4-layer simplification of the 3-D model by Behm et al. (2007).

\section{Seismic data}

For our research, we used the data from the Ebreichsdorf 2013 earthquake series, which was located by Apoloner and Bokelmann (2015) with all available data within $230 \mathrm{~km}$ and the 3-D velocity model by Behm et al. (2007). For modeling the wave propagation we used the largest event with a local magnitude of 4.2 and a depth of $10.5 \mathrm{~km}$. Also, this is one of the earthquakes in the Vienna Basin where a focal mechanism was published. From this dataset we selected the six earthquakes with local magnitudes above 2.0, which are listed in Table 1. Most important for this study the events were also recorded at the seismic array GERES in Germany . The array consists of 21 1-component and four 3-component seismic stations depicted in Fig. 1 which have been continuously recording since 1991 (Harjes et al., 1993). The array is at a distance of approximately $220 \mathrm{~km}$ from our area of interest and has a backazimuth of $115^{\circ}$ to the selected events. 
Table 1. Hypocentral parameters of earthquakes with local magnitude above 2.0 from Apoloner and Bokelmann (2015) sorted by focal depth

\begin{tabular}{rrcccr}
\hline ID & $\begin{array}{r}\text { Origin Time } \\
(\text { UTC) }\end{array}$ & $\begin{array}{c}\text { Ml } \\
(\text { ZAMG })\end{array}$ & $\begin{array}{c}\text { Longitude } \\
{[\mathrm{deg}]}\end{array}$ & $\begin{array}{c}\text { Latitude } \\
{[\mathrm{deg}]}\end{array}$ & $\begin{array}{r}\text { Depth } \\
{[\mathrm{km}]}\end{array}$ \\
\hline A & 20 Sep 2013 02:06 & 4.2 & 16.4230 & 47.9318 & 10.5 \\
B & 2 Oct 2013 17:17 & 4.2 & 16.4229 & 47.9315 & 10.5 \\
C & 2 Oct 2013 19:42 & 2.8 & 16.4210 & 47.9324 & 10.0 \\
D & 24 Sep 2013 13:53 & 2.7 & 16.4207 & 47.9322 & 9.8 \\
E & 23 Oct 2013 19:34 & 2.6 & 16.4202 & 47.9321 & 9.6 \\
F & 2 Oct 2013 05:26 & 2.1 & 16.4237 & 47.9343 & 8.9 \\
\hline
\end{tabular}

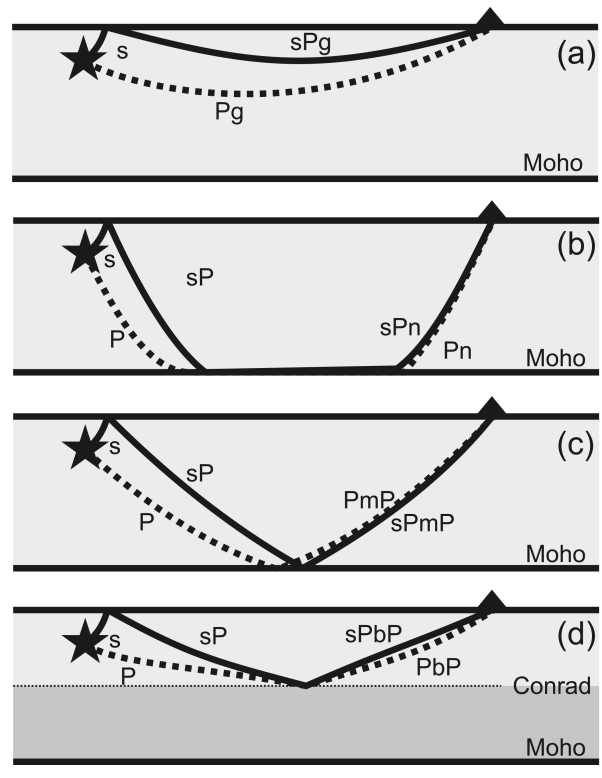

Figure 2. Sketch figure for different RDP wavepaths adapted from Ma and Eaton (2011): (a) Pg and sPg, (b) Pn and sPn, (c) Moho reflection PmP and sPmP, augmented by (d) Mid crust reflection $\mathrm{PbP}$ and $\mathrm{sPbP}$.

\section{Regional Depth Phase (RDP) propagation}

Regional depth phases such as $\mathrm{sPg}, \mathrm{sPmP}$ and $\mathrm{sPn}$ in combination with their reference phases $\mathrm{Pg}, \mathrm{PmP}$ and $\mathrm{Pn}$ can be used to estimate focal depths of regional earthquakes, if they can be identified. Figure 2 sketches their wavepaths. In principle, a single station with one phase pair may be sufficient for accurately determining earthquake depth from the difference in their arrival times. Different studies, e.g., Ma and Eaton (2011) and Ma (2012) mention that regional depth phases depend mainly on epicentral distance: Between 200 and $300 \mathrm{~km}$ waveforms should be quite simple: a weak Pn is followed by a strong PmP and sPmP using a simple 2-layer model and a thrust type mechanism.

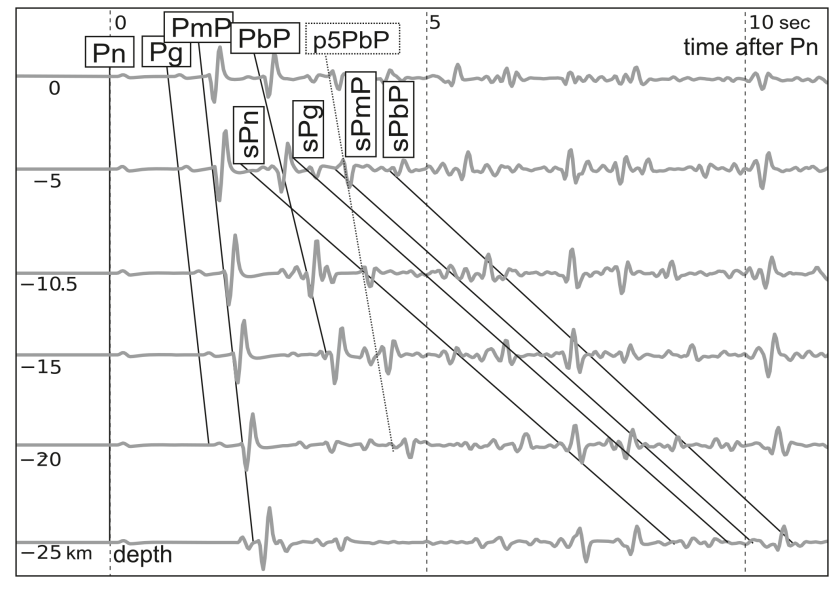

Figure 3. Synthetic seismograms of the vertical component for the central array station GEA0 for depths ranging from 0 to $25 \mathrm{~km}$. Phases are arrivals annotated ackording to wave type. e.g. sPn seems to be visible, but is strongly overlapped by other phases. In addition to the RDPs, the $\mathrm{p} 5 \mathrm{PbP}$ is recognizable.

\subsection{Waveform modeling}

In the first part of this study we model RDP propagation for the tectonic setting and seismic data in our area of interest. Using the velocity model by Hausmann et al. (2010) and the focal mechanism by Hausmann et al. (2014), the source time function was estimated for both Ml 4.2 earthquakes with empirical Green functions and is approximated by a $0.2 \mathrm{~s}$ parabolic pulse. With those parameters synthetic seismograms were calculated using the wavenumber integration implemented by Herrmann (2013) for all stations of the array and for depths ranging from 0 to $25 \mathrm{~km}$.

To gain an overview on lateral propagation behavior of RDP, we additionally calculated synthetic seismograms in a regular spaced grid around Ebreichsdorf up to $400 \mathrm{~km}$ distance. However, Fig. 3 shows the results for the closest grid point at an azimuth of $295^{\circ}$ and $220 \mathrm{~km}$ distance, to facilitate comparison of the results to the next processing step.

To give an overview RDP propagation we processed the synthetic data as follows: we measure the maximum amplitude of arriving RDPs on the horizontal component velocity 


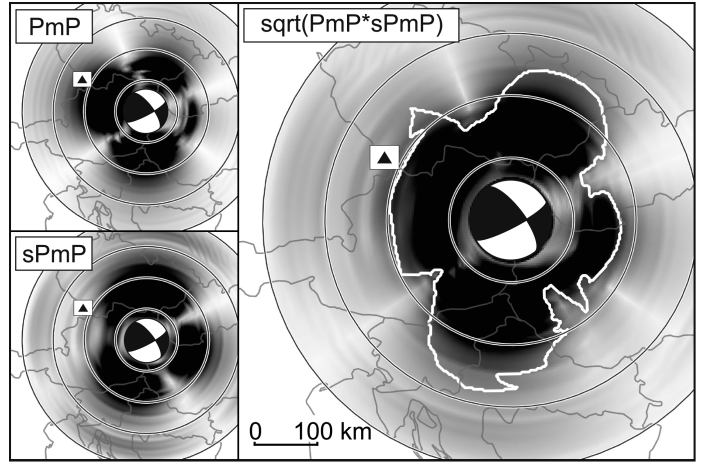

Figure 4. Lateral propagation of PmP (top left panel) and $\mathrm{sPmP}$ (bottom left panel) for a strike-slip earthquake in Ebreichsdorf at $10.5 \mathrm{~km}$ depth from synthetic traces: right panel shows combined strength of phases (grey shades) and area of minimal visible amplitude for both phases (white line).

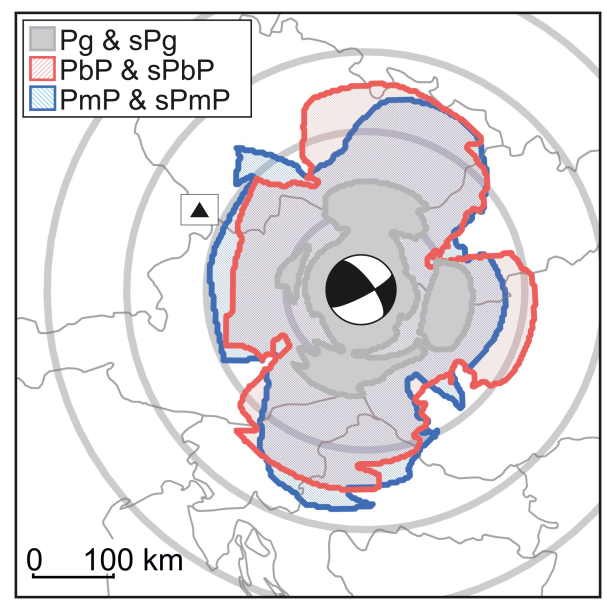

Figure 5. Areas of visibility for both phases of a depth phase pair derived from synthetic seismograms

record envelope for each grid point. Afterwards, we multiply those values for each phase pair at each grid point and normalize their power by extracting the square root. The interpolated results are shown in Fig. 4 superimposed on our area of interest. Dark coloring indicates high amplitudes for at least one phase of a depth

However, for depth estimation it is advantageous, though not necessary, to identify both. For this reason, we extract the area where both phases of a pair should have a significant amplitude. Based on the synthetic traces and real data from GERES, we know that we can identify PmP and PbP. Therefore, we assume that half the amplitude of PmP should be still visible. We draw a contour line around the area where each phase is above this minimum value and intersect the contours for each phase pair. The result for PmP and sPmP is shown in Fig. 4 in the right panel. Figure 5 puts together the contour lines for different depth phase pairs.

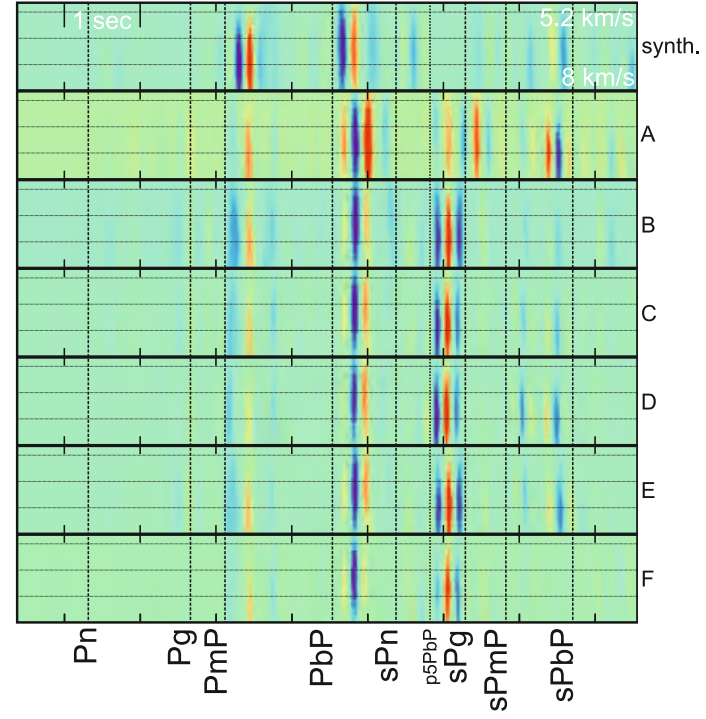

Figure 6. Vespagrams for synthetic data for the first earthquake at GERES and real data for all selected earthquakes from Table 1. Vespagrams are aligned on PmP arrival and phases were calculated with TauP of Crotwell and Owens (2011).

\section{Array analysis with vespagrams}

The synthetic traces in Fig. 3 as well as the spreading maps in Fig. 4 and 5 show, that PmP and PbP should be visible clearly because of their high amplitudes at GERES. However, $S$ to $P$ conversions like $\mathrm{sPmP}$ and $\mathrm{sPbP}$ are not visible. As mentioned before array processing can be used to improve SNR of time series by, e.g. creating vespagrams. Figure 6 shows the results for all earthquakes in our dataset in color and for the synthetics of the first earthquake A.

\section{Polarization analysis of 3-component stations}

Most elements of GERES are only recording the vertical movement. This is sufficient to identify backazimuth and slowness by array processing. However, GERES does also have four 3-component sensors, which are shown in the top left panel in Fig. 1. In the next step we try to use those stations to identify the phases visible in the vespagrams, using their polarization. For polarization analysis we used the method introduced by Vidale (1986). Figure 7 shows the results for earthquakes A to E in grey and for the synthetics of the first event in black. Earthquake F was not used because of low SNR due to the small magnitude.

\section{Results}

\subsection{Regional depth phase spreading}

The different propagation patterns for $\mathrm{PmP}$ and $\mathrm{sPmP}$ are shown in Fig. 4, together with the combination of both. Wave propagation for our dataset with a four layer model and a 


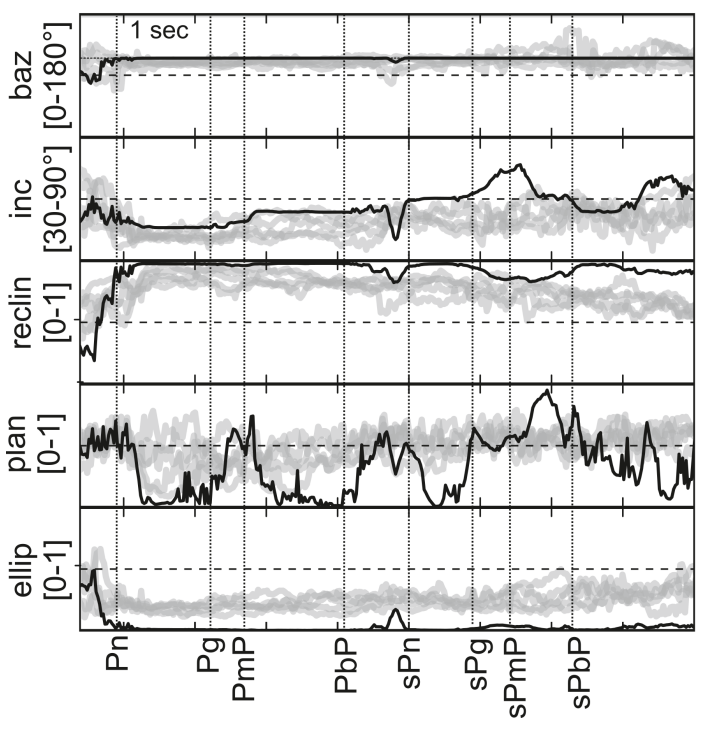

Figure 7. Polarization analysis for synthetic data (black) and earthquakes (grey). From top to bottom: backazimuth, incidence angle, rectilinearity, planarity and ellipticity.

strike-slip mechanism is more complex than anticipated from literature, which, among other factors assumes that the mechanism is not relevant. The PmP phase has propagation pattern like a $P$ wave with four lobes with strong amplitudes between 100 and $200 \mathrm{~km}$. On the other hand, the sPmP propagates like a $S$ wave but is stronger at up to $90^{\circ}$ azimuth to the PmP and a similar distance range. The areas where both phases are likely to be identified are depicted in the right panel in Fig. 4. Depending on the azimuth distances between 50 and $250 \mathrm{~km}$ can have strong amplitudes.

Figure 5 shows the outlines of three different depth phase combinations for our area of interest. Interestingly also the $\mathrm{PbP}$ and $\mathrm{sPbP}$ phase pair, which has not been used for depth estimations, shows a similar pattern to PmP and sPmP phases. Pg and sPg also show strong azimuth dependence.

\subsection{Array analysis}

The vespagrams for our data in Fig. 6 show a clear pattern for all earthquakes, which is also visible in the synthetics: A strong PmP with an apparent velocity of $7 \mathrm{~km} \mathrm{~s}^{-1}$ is followed by an even stronger $\mathrm{PbP}$ at $6.2 \mathrm{~km} \mathrm{~s}^{-1}$ even for our smallest used magnitudes. $\mathrm{PbP}$ arrives later than calculated, which indicated either a deeper Conrad discontinuity or higher velocities above it.

However, another strong phase follows with a high amplitude in the real data, shortly before the sPg. In the synthetics this phase is also visible and the most likely wavepath is an upward going $P$ wave which reflects at the $5 \mathrm{~km}$ interface in the model and then propagates as $\mathrm{PbP}(\mathrm{p} 5 \mathrm{PbP})$. The high amplitude indicates a depth below this interface and above the Conrad discontinuity. Also, the downwards reflection hap- pens very close to the earthquakes, which would relate to a downward reflection from the bottom of the Vienna Basin.

Converted depth phases like $\mathrm{sPg}, \mathrm{sPmP}$ and $\mathrm{sPbP}$ are not visible. Although we could not identify depth phases, depth is restricted since we know from modelling that a strong $\mathrm{PbP}$ is only possible for sources above the Conrad.

Furthermore, it is important to notice that $\mathrm{PmP}$ is the by far strongest phase arriving at GERES. This can lead to errors in location if it is mistaken for the Pn phase, which is the first arrival, but has much less energy.

The figures above show the results of the vespagrams of an event at GERES. The top figure shows the result for the recorded data, the bottom one for the synthetics. Although the Pn onset is clearly visible after processing, other phases cannot be identified because they occur very close to each other.

\subsection{Polarization analysis}

In the last step we analysed the polarization of data and compared it to the synthetic results (see Fig. 7). For the beginning of the $P$ coda analysed by us the backazimuth stays stable at the estimated $115.5^{\circ}$. Inclination changes with the different phases arriving, in clear steps for the synthetic data and slowly for the real data. Planarity and ellipticity do not show a clear signal.

The Pn onset is clearly visible in backazimuth, incidence and rectilinearity down to a local magnitude of 2.6. Earthquake $\mathrm{F}$ with a $\mathrm{Ml}$ of 2.1 does not even show this feature and therefore was excluded.

\section{Conclusions}

Lateral analysis of synthetic data shows that regional depth phase propagation is strongly dependent not only on depth but also on the focal mechanism. Therefore, the knowledge of focal mechanism is important and a typical mechanism for the area needs to be used. Also, additional layers in the underground can produce strong reflections not reported by literature like $\mathrm{PbP}$ or $\mathrm{p} 5 \mathrm{PbP}$. Although no RDP pair could be identified, the visible regional phases restrict depth of the events in our dataset between a layer above and below the earthquakes, which relate to the bottom of the Vienna Basin and the Conrad discontinuity.

From comparison of the afore mentioned results to our dataset, we conclude that earthquakes from the Vienna Basin develop clear PmP and PbP arrivals at GERES. However, the converted depth phases $\mathrm{sPn}, \mathrm{sPg}, \mathrm{sPmP}$ and $\mathrm{sPbP}$ are not visible, not even with the improved SNR of the array. Yet, vespagram analysis can be used to identify phases in the $P$ coda by their slowness even down to magnitudes of 2.1.

Further research will analyse RDP propagation around the Vienna Basin in more detail. One important feature that needs to be addressed is the low-velocity sediment layer, which is reported to weaken converted phases we are looking 
for. Also, we will investigate data from our dataset recorded at stations, which are in areas where the synthetics indicate high amplitudes for RDPs. Since time difference between RDP pairs is mainly affected by depth, as stated in Ma (2010), it should be possible to use phase readings of single phases at varying distances to estimate depth.

With newly deployed dense seismic network like the AlpArray presented in Fuchs et al. (2015) or profiles like EASI (see Plomerova et al. (2015) wave propagation could be monitored and maybe even tracked across the region. This extended knowledge of RDP behaviour can then be used to locate even small earthquakes more accurately as more information than first picks is available.

Acknowledgements. We thank the Zentralanstalt für Meteorologie und Geodynamik (ZAMG) and the Bundesanstalt für Geowissenschaften und Rohstoffe (BGR) for making available seismic data for this study. Plots were created with ObsPy (Beyreuther et al., 2010) and maps with QGIS (QGIS, 2009). Synthetics were generated with Computer Programs in Seismology by Herrmann (2013). Travel times were calculated with TauP (Crotwell and Owens, 2011).

Edited by: D. Pesaresi

Reviewed by: two anonymous referees

\section{References}

Apoloner, M.-T. and Bokelmann, G.: Ebreichsdorf 2013 Earthquake Series: Relative Location, in: EGU General Assembly, 12-17 April 2015, Vienna, Austria, 2015.

Behm, M., Brückl, E., and Mitterbauer, U.: A New Seismic Model of the Eastern Alps and its Relevance for Geodesy and Geodynamics, VGI Österrreichische Zeitschrift für Vermessung \& Geoinformation, 2, 121-133, 2007.

Beyreuther, M., Barsch, R., Krischer, L., Megies, T., Behr, Y., and Wassermann, J.: ObsPy: A Python Toolbox for Seismology, Seismol. Res. Lett., 81, 530-533, 2010.

Brückl, E., Behm, M., Decker, K., Grad, M., Guterch, A., Keller, G. R., and Thybo, H.: Crustal structure and active tectonics in the Eastern Alps, Tectonics, 29, doi:10.1029/2009TC002491, 2010.

Crotwell, H. P. and Owens, T. J.: The TauP Toolkit: Flexible Seismic Travel-Time and Raypath Utilities Documentation Version 2.0, 2011.

Fuchs, F., Bokelmann, G., Bianchi, I., Apoloner, M.-T., and Group, A. W.: AlpArray Austria - Illuminating the subsurface of Austria and understanding of Alpine geodynamics, in: EGU General Assembly, 12-17 April 2015, Vienna, Austria, 2015.
Harjes, H.-P.: Design and siting of a new regional array in Central Europe, B. Seismol. Soc. Am., 80, 1801-1817, 1990.

Harjes, H.-P., Jost, M. L., Schweitzer, J., and Gestermann, N.: Automatic Seismogram Analysis at GERESS, Comput. Geosci., 19, 157-166, doi:10.1016/0098-3004(93)90113-J, 1993.

Hausmann, H., Hoyer, S., Schurr, B., Brückl, E., Houseman, G., and Stuart, G.: New Seismic Data improve earthquake location in the Vienna Basin Area, Austria, Austrian Journal of Earth Sciences, 103, 2-14, 2010.

Hausmann, H., Meurers, R., and Horn, N.: The 2013 Earthquakes in the Vienna Basin: Results from strong-motion and macroseismic data, in: Second European Conference of Earthquake Engineering and Seismology, Istanbul, Turkey, 2014.

Herrmann, R. B.: Computer programs in seismology: An evolving tool for instruction and research, Seismol. Res. Lett., 84, 10811088, doi:10.1785/0220110096, 2013.

Ma, S.: Focal Depth Determination for Moderate and Small Earthquakes by Modeling Regional Depth Phases sPg, sPmP, and sPn, B. Seismol. Soc. Am., 100, 1073-1088, doi:10.1785/0120090103, 2010.

Ma, S.: Earthquake Research and Analysis - Seismology, Seismotectonic and Earthquake Geology, chap. Focal Depth Determination for Moderate and Small Earthquakes by Modeling Regional Depth Phases sPg, sPmP, and sPn, InTech, 143-166, doi:10.5772/27240, 2012.

Ma, S. and Atkinson, G. M.: Focal Depths for Small to Moderate Earthquakes, B. Seismol. Soc. Am., 96, 609-623, doi:10.1785/0120040192, 2006.

Ma, S. and Eaton, D. W.: Combining Double-Difference Relocation with Regional Depth-Phase Modelling to Improve Hypocentre Accuracy, Geophys. J. Int., 185, 871-889, doi:10.1111/j.1365246X.2011.04972.x, 2011.

Plomerova, J., Bianchi, I., Hetényi, G., Munzarová, H., Bokelmann, G., Kissling, E., AlpArray-EASI-Working-Group, and AlpArray-EASI-Field-Team: The Eastern Alpine Seismic Investigation (EASI) project, in: EGU General Assembly, 12-17 April 2015, Vienna, Austria, 2015.

QGIS, D. T.: QGIS Geographic Information System, Open Source Geospatial Foundation, available at: http://qgis.osgeo.org (last access: 31. August 2015), 2009.

Rost, S. and Thomas, C.: Array Seismology: Methods and Applications, Rev. Geophysics, 40, 2-1-2-27, doi:10.1029/2000RG000100, 1008, 2002.

Vidale, J. E.: Complex polarization analysis of particle motion, B. Seismol. Soc. Am., 76, 1393-1405, 1986.

Wessely, G.: Zur Geologie und Hydrodynamik im südlichen Wiener Becken und seiner Randzone, Mitteilungen der österreichischen geologischen Gesellschaft, 76, 27-68, 1983. 